\title{
Attitudes Toward a Military Enforcement of Human Rights
}

\author{
Detlef Fetchenhauer $^{1,2}$ and Hans-Werner Bierhoff ${ }^{2}$
}

In recent years, Western countries and NATO have repeatedly intervened in international conflicts using military means (e.g., Kosovo, Macedonia, and Afghanistan). The countries involved in these military operations have stated that these interventions did not serve strategic goals; instead, their prime purpose was to enforce human rights. Against this background the present paper aims to answer two main questions: First, how can attitudes toward such military interventions be measured? Second, how are these attitudes related to prosocial and antisocial personality dispositions? Two studies were conducted to address these questions. A first study with 275 university students from Germany enabled us to develop a short and reliable scale to measure attitudes toward the military enforcement of human right. A second study $(N=190)$ revealed that authoritarianism and the willingness to aggressively sanction the antisocial behavior of others were positively related to this attitude, while no significant relationship with prosocial dispositions emerged. Furthermore, it could be shown that a high concern for human rights only then was connected to a positive attitude toward their military enforcement if persons indicated to handle their daily conflicts in an aggressive manner.

KEY WORDS: military interventions; war; human rights; social responsibility; authoritarianism.

\section{INTRODUCTION}

In recent years, Western countries have repeatedly conducted military interventions in other countries (e.g., Kosovo, Macedonia, Afghanistan, and Iraq).

\footnotetext{
${ }^{1}$ Inter-University Center for Social Science Theory and Methodology, University of Groningen, Groningen, The Netherlands.

${ }^{2}$ Department of Social Psychology, University of Bochum, Bochum, Germany.

${ }^{3}$ All correspondence should be addressed to Detlef Fetchenhauer, ICS, University of Groningen, Grote Rozenstraat 31,9712 TG Groningen, The Netherlands; e-mail: d.fetchenhauer@ppsw.rug.nl.
} 
Countries that were involved in such interventions argued that these military interventions did not serve strategic interests but were meant to enforce human rights in nondemocratic countries. This reasoning referred to a rather new dimension of engagement for human rights. Up to the bombing of Serbian cities by NATO airplanes in 1999, measures to realize this aim had mainly been political pressure, help for the victims, or economic sanctions. Through NATO's intervention into the conflict between Serbs and Albanians in the Kosovo conflict, a new measure for the enforcement of human rights-namely military intervention-was introduced. The goal of the present research was to examine the reliability and validity of a newly developed scale to measure the attitude toward such military interventions. Beyond that, the aim of the present research was to investigate how the attitude toward a military enforcement of human rights is related to prosocial and antisocial dispositions, civil engagement for human rights, and to the political orientation and the gender of respondents, respectively.

These variables and theoretical concepts were not chosen arbitrarily. The main theoretical focus of this selection was the question whether an endorsement of a military enforcement of human rights in nondemocratic countries is related to being a rather antisocial or a rather prosocial personality. Is a positive attitude toward such wars an indicator of aggressiveness and authoritarianism or does it reflect a sense of duty to help suppressed people that suffer from brutal dictators?

\section{Authoritarianism}

A number of studies show that a high degree of authoritarianism is related to low commitment toward human rights even in one's own country (Altemeyer, 1996; Moghaddam and Vuksanovic, 1990). Therefore, a negative relationship between authoritarianism and concern for human rights was predicted.

With regard to the relationship between authoritarianism and the attitude toward a military enforcement of human rights, both a negative and a positive correlation seems plausible. On the one hand, high authoritarians should not care very much about the violation of human rights in other countries because authoritarianism is positively related to ethnocentrism (which implies that someone is not very much concerned about the social situation in other countries; Altemeyer, 1996). Therefore, it can be expected that high authoritarians would not be willing to sacrifice the lives of fellow countrymen for the enforcement of human rights in foreign countries. On the other hand, it has been repeatedly shown that people scoring high on authoritarianism have a high willingness to solve societal problems by means of violence and that they indicate a high level of punitivity (i.e., the willingness to punish people who do not follow social or legal norms; e.g., Feather, 1996). For this reason, authoritarianism might be positively related to the willingness of people to enforce human rights by military means, especially if this is backed by accepted state authorities (cf. Altemeyer, 1998). Because in most 
cases of NATO intervention the risk of losses for own soldiers is quite low, we expected that authoritarianism would be a positive correlate of a preference for violent enforcement of human rights.

\section{Political Orientation}

Traditionally, there is a positive relationship between the acceptance of war and violence to solve political conflicts, on the one hand, and right-wing political attitudes, on the other hand (Altemeyer, 1996; Kerlinger, 1984). Thus, a positive correlation between conservatism and the attitude toward a military enforcement of human rights might be expected. However, as Braithwaite (1998) has shown, people with a left-wing orientation are more likely than people with a right-wing orientation to adhere to values like "international harmony and equality" and "humanitarianism." Thus, it appears to be an open question whether there will be a significant relationship between political orientation and attitudes toward the military enforcement of human rights. Whereas the goal of enforcing human rights seems to be more in line with the value system of "liberals" (i.e., people with a left-wing political attitude) the use of military means to reach such a goal seems to be more in line with the value system of "conservatives" (i.e., people with a right-wing political attitude).

\section{Sanctioning the Antisocial Behavior of Others}

How do people react if they observe others violating social norms and behaving in an antisocial way? Fetchenhauer (Fetchenhauer, D. The Willingness to sanction the antisocial behavior of others. Development of a new personality scale, in preparation) has developed a list of 10 different vignettes that describe a variety of antisocial behaviors of a stimulus-person in different social settings. Examples of these vignettes are, "observing that someone throws his garbage on the floor although there is a trashcan nearby," "watching a person who does not seem to be handicapped park his or her car in a parking space that is reserved for handicapped people," or "witnessing that a drunk person wants to drive home with his own car." According to each vignette, respondents are asked whether they would kindly ask the stimulus-person to stop her antisocial behavior (constructive sanctioning). Furthermore, respondents are asked whether they could imagine to become aggressive toward the stimulus-person if he/she did not stop his or her antisocial behavior after being kindly asked to do so (aggressive sanctioning).

Studies conducted so far show constructive sanctioning and aggressive sanctioning to be rather independent from each other. In these studies (using both student samples and national representative samples), constructive sanctioning was positively related to prosocial dispositions like justice sensitivity with regards to the 
unfair treatment of others (for the concept of justice sensitivity see Fetchenhauer and Huang, in press; Schmitt et al., 1995), social responsibility, and agreeableness. Furthermore, constructive sanctioning was positively related to conscientiousness. Conversely, aggressive sanctioning was mainly related to a number of rather antisocial dispositions like machiavellism and authoritarianism. In addition, aggressive sanctioning was negatively related to extraversion (possibly indicating that those scoring high on aggressive sanctioning might lack the interpersonal skills to approach antisocial others in a friendly and constructive manner). To summarize, constructive sanctioning seems to be related to the perceived duty to intervene if one observes some antisocial behavior of others (for the concept of duties see Moghaddam et al., 2000), whereas aggressive sanctioning seems to be mainly related to punitivity.

We expected the attitude toward military interventions to be positively related to aggressive sanctioning because both dimensions imply a willingness to punish violators of social norms in a militant and harsh way. On the contrary, given the low correlations between aggressive sanctioning and constructive sanctioning in previous studies, we did not expect a significant relation between constructive sanctioning and attitudes toward a military enforcement of human rights.

\section{Social Responsibility}

According to Berkowitz and Daniels (1964), people systematically differ in their level of social responsibility (i.e., the extent to which they feel responsible for the well-being of other people). Given that the concept of social responsibility implies helpful behavior to friends as well as to strangers, it can be expected that high values on this dimension are positively related to a general concern for human rights because persons with a high level of social responsibility should feel affected by the suffering of people in other countries. This assumption is backed by a study of Spini and Doise (1998) in which personal engagement for the enforcement of human rights was positively related to values such as benevolence and universalism (values that can be regarded as indicators of a prosocial orientation).

However, it appears difficult to predict how social responsibility and attitudes toward military enforcement of human rights are related. On the one hand, it seems plausible that both variables are negatively correlated because people with a high level of social responsibility might be especially aware of the fact that the suffering and death of innocent people is an inevitable consequence of the use of military force. On the other hand, it is also conceivable that both variables are positively correlated because high levels of social responsibility might lead persons to argue that the violation of human rights cannot be accepted under any circumstance. Bierhoff and Rohmann (in press) showed that the relationship between social responsibility and prosocial behavior depends on the underlying situation and cognitive processes. Thus, it seems impossible to predict whether a high emphasis 
on social responsibility will make the person focus on the innocent victims of military interventions or on the victims of an ongoing violation of human rights.

\section{Civil Engagement for Human Rights}

Previous research that examined attitudes toward the enforcement of human rights focused on the mental structures of concern and civil engagement for human rights and its relationship to general value orientations (see the studies by Doise and his coworkers, e.g., Doise et al., 1994; Spini and Doise, 1998; Staerkle et al., 1998). But what is the relation between such civil engagement for human rights and the attitude toward their military enforcement? To answer this question one must consider opposing processes. On the one hand, a high level of concern for the enforcement of human rights (e.g., the willingness to participate in campaigns of Amnesty International) might lead to a more positive attitude toward military interventions because such interventions might be regarded as a necessary evil. On the other hand, concern for human rights might be related to a high degree of pacifism and a preference for not using violence to solve social conflicts. If so, concern for human rights would be negatively related to the willingness to enforce these rights with military means. Our general prediction (i.e., without considering moderator variables) is that concern for human rights and the attitude toward a military enforcement of human rights are independent of each other because both processes described above tend to neutralize each other.

More specifically, our assumption is that the relationship between both variables is moderated by a person's level of aggressive sanctioning. At a low level of aggressive sanctioning, we expected concern for human rights to be rather unrelated to attitudes toward their military enforcement. At a high level of aggressive sanctioning, a positive correlation between traditional concern for human rights and the attitude toward a military enforcement of human rights was expected.

\section{Gender}

A vast number of studies show that women and men differ in their attitudes toward war and violence (e.g., Baxter and Lansing, 1980). One theoretical explanation for this finding is that men and women differ in their way of moral reasoning. According to Gilligan (1982) men mainly follow an ethics of justice, which implies a strong concern for following abstract social rules and norms. Contrary, women follow rather an ethics of care, which implies a strong emphasis on maintaining social relations and paying attention to the situational needs of others. Therefore, we expected men to have a more positive attitude toward the military enforcement of human rights than women. 


\section{Present Research}

We conducted two studies to develop a questionnaire to measure the attitude toward military violence as a means to enforce human rights and to examine the hypotheses outlined above.

\section{STUDY 1}

To measure the attitude toward military enforcement of human rights, 26 items were developed covering a broad range of issues that are related to that topic. The items included statements that tapped the moral legitimacy of the use of military means and the desire for more military interventions of the NATO in the future. Furthermore, respondents were asked whether they would be willing to personally sacrifice own resources for the military enforcement of human rights and how they thought about legal issues that are related to military interventions in other countries (e.g., without a mandate of the United Nations). The items covered a broad range of issues; however, they did not measure a general attitude toward war and the use of military violence to solve international conflicts. Rather, all items were concerned with the specific problem of enforcement of human rights in nondemocratic countries.

\section{Methods and Participants}

This 26-item measure was distributed to a sample of 275 law students at the University of Bochum, which is located in an industrial region in the western part of Germany. Respondents were either in their first or second year of their study program. As to gender, $45.5 \%(N=126)$ of all participants were male and $54.7 \%$ $(N=152)$ were female. The mean age was 21.0 years. The degree of agreement with regard to the 26 items was indicated on 7-point Likert scales with the endpoints "totally disagree" and "totally agree."

\section{RESULTS}

To assess the dimensionality of the 26 items an exploratory factor analysis (Varimax rotation) was conducted, which revealed five factors with eigenvalues $>1$. On the basis of these five factors, five different subscales were formed (Cronbach's alpha ranged from 0.69 to 0.91 ).

The first factor comprised 11 items and explained $20.9 \%$ of the total variance. These 11 items formed one unitary scale that was labeled Legitimacy of Military Means (Cronbach's $\alpha=0.91$ ), the item with the highest factor loading being "It's 
a pity if innocent people are killed in military strikes against dictators. However, such occurrences are simply unavoidable."

The second factor included four items explaining $11.5 \%$ of the variance. These four items were able to be integrated into a scale called Request for Future NATO Interventions including items like "I wish NATO would intervene in all countries in which human rights are violated" (Cronbach's $\alpha=0.71$ ).

The third factor (explaining 10.3\% variance) mainly included judgments about the need to invest in special military units for short-term interventions (e.g., "The enforcement of human rights is becoming more and more a question of military efficiency. For this reason the number of specialized military units should be increased"). Cronbach's alpha of this four-item scale was 0.78 (labeled Willingness to Invest in Future Military Peace Missions).

The fourth factor also comprised four items and accounted for $9.7 \%$ of the variance measuring the willingness to accept personal disadvantages for the military enforcement of human rights (Cronbach's $\alpha=0.72$ ). The items indicated the willingness to accept cuts in the social budget if money is needed for military interventions (e.g., "I support military actions against violations of human rights in nondemocratic countries even if this leads to cuts in the social budget of my own country.'), but also the willingness to risk a nuclear war for the enforcement of human rights. Hence, this scale was called Willingness to Sacrifice Own Resources for Military Interventions.

The last factor included items that were related to legal issues of military interventions (e.g., "If a country is systematically violating human rights, it is alright to build protectorates on its territory"), explaining 7.4\% variance. Hence, these three items were integrated into a scale labeled Evaluation of Military Interventions from the perspective of International Law (Cronbach's $\alpha=0.69$ ).

Although these five different factors could be interpreted in a meaningful way, the question remained whether they represent different, autonomous subdimensions or are parts of a one-dimensional attitude. One argument supporting the latter view is found in the order of the eigenvalues of five different factors. Whereas all five factors had eigenvalues $>1$, the eigenvalue of the first factor was much larger than that of the other factors (the eigenvalues before Varimax rotation being 9.6, 1.9, 1.6, 1.2, and 1.2, respectively). Furthermore, all five subdimensions correlated substantially with each other (the average correlation being $r=0.51$ ). To further test whether these five factors could be integrated into one single dimension, a second-order factor analysis was conducted using the correlations between the five different scales as input. This factor analysis revealed only one factor with an eigenvalue $>1$ (explaining $60.8 \%$ of the variance).

Therefore, a 26-item global scale was formed that turned out to be highly homogeneous (Cronbach's $\alpha=0.93$ ), the average (corrected) item-total correlation being $r=0.56$. To investigate whether this scale could be shortened without losing too much of its homogeneity, a 10-item version of the scale was developed (using the item's correlation with the total score as the criterion of selection). 
Table I. The ATMEHR (Attitude Toward Military Enforcement of Human Rights): Items, Means, Standard Deviations and Item-Total Correlations (Study 2)

\begin{tabular}{|c|c|c|}
\hline Item & $M(\mathrm{SD})$ & $\begin{array}{l}\text { Item-total } \\
\text { correlation }\end{array}$ \\
\hline $\begin{array}{l}\text { It is a sign of a humanitarian attitude to use military } \\
\text { means to stop violations of human rights }\end{array}$ & $3.0(1.5)$ & 0.68 \\
\hline $\begin{array}{l}\text { One has always tried to enforce human rights via negotiations. } \\
\text { However, sometimes there are cases where the only } \\
\text { alternative is military force }\end{array}$ & $3.8(1.5)$ & 0.70 \\
\hline $\begin{array}{l}\text { The enforcement of human rights is becoming more and more a } \\
\text { military task. Therefore, NATO's military units that are } \\
\text { especially equipped for such interventions should be enlarged }\end{array}$ & $2.9(1.5)$ & 0.68 \\
\hline $\begin{array}{l}\text { Generally speaking I object to war as a means of politics. However, } \\
\text { in the case of the enforcement of human rights it's } \\
\text { a different matter }\end{array}$ & $3.2(1.5)$ & 0.70 \\
\hline $\begin{array}{l}\text { I wish NATO would intervene in all countries in which } \\
\text { human rights are violated }\end{array}$ & $3.2(1.5)$ & 0.60 \\
\hline $\begin{array}{l}\text { NATO's troops should be enlarged so that they can intervene more } \\
\text { easily in countries that violate human rights }\end{array}$ & $2.7(1.5)$ & 0.63 \\
\hline $\begin{array}{l}\text { I support military actions against violations of human rights in } \\
\text { nondemocratic countries even if this leads to cuts in the } \\
\text { social budget of my own country }\end{array}$ & $3.0(1.6)$ & 0.60 \\
\hline $\begin{array}{l}\text { The idea of securing peace without war is unrealistic. In some } \\
\text { regions of the world it is simply necessary to use } \\
\text { military means to enforce human rights }\end{array}$ & $2.7(1.4)$ & 0.62 \\
\hline $\begin{array}{l}\text { It is paradox to try to enforce human rights by military } \\
\text { means (to be reversed) }\end{array}$ & $4.2(1.6)$ & 0.69 \\
\hline $\begin{array}{l}\text { It is better to go to war for several months than to accept } \\
\text { violations of human rights for an indefinite } \\
\text { period of time }\end{array}$ & $3.4(1.5)$ & 0.70 \\
\hline
\end{tabular}

The homogeneity of this shortened global scale appeared to be sufficiently high (Cronbach's $\alpha=0.90$ ); the average item total correlation was $r=0.66$. The homogeneity of this short scale was also confirmed by a factor analysis that was run with the 10 items. Only one factor reached an eigenvalue $>1(=5.7)$ explaining $57 \%$ of the variance. The correlation between the 26 -item and the 10 -item version was $r=0.94$.

Six of the ten items originally loaded on the first factor (Legitimacy of Military Means), one item on the second factor (Request for Future NATO Interventions), two items on the third factor (Willingness to Invest in Future Military Peace Missions), and one item on the fourth factor (Willingness to Sacrifice Own Resources for Military Interventions) (for the wording of these 10 items see Table I).

Because the ratings for all 10 items were added and divided by 10 , the scores of the scale had a theoretical range from 1 to 7 with high scale values denoting positive attitudes toward the military enforcement of human rights. The mean response was $M=3.7(S D=1.25)$ indicating that the average participant held an attitude toward military interventions that was neither strictly negative nor positive. Kurtosis was -0.49 and skewness was -0.01 . 
The aim of Study 1 was to develop a reliable and relatively short scale to measure the attitude toward military interventions in the context of the enforcement of human rights in nondemocratic countries. Analysis of the 26 items of the initial questionnaire revealed that these items are represented by five different yet highly interrelated subdimensions. Thus, it was possible to integrate the five subdimensions in one homogeneous 10-item scale, which presumably measures the overall Attitude toward a Military Enforcement of Human Rights (ATMEHR). This scale taps a person's belief that the use of military power is legitimate from a moral point of view, more NATO interventions are recommended in the future, and money should be invested into military units that are specially trained for such interventions even if this means cutbacks in the social budget of one's own country. The high homogeneity of the ATMEHR scale indicates that participants expressed a quite consistent attitude toward this matter.

\section{STUDY II}

The aim of Study II was to replicate the results of Study I with regard to the ATMEHR scale's reliability and to investigate how the attitude toward a military enforcement of human rights is related to the personality dispositions and demographic variables that were discussed in the introduction of this paper.

\section{Sample and Methods}

Participants of this study were 76 law students and 114 psychology students of the University of Bochum (thus, the total sample consisted of $N=190$ participants). In this sample, $28.9 \%$ of all respondents were males and $71.1 \%$ were females. The mean age of the respondents was 24.3.

Social responsibility was measured with the German version (Bierhoff, 2000) of the Social Responsibility Scale (SRS) by Berkowitz and Daniels (1964). This scale consists of 22 items with a range of 1-6. Cronbach's alpha was 0.71, the mean was $5.02(\mathrm{SD}=0.41)$. Thus, respondents portrayed themselves to be rather highly socially responsible.

Authoritarianism was measured by a short version of Altemeyer's Right Wing Authoritarianism scale (RWA; Altemeyer, 1996). This version comprised 10 items (Cronbach's $\alpha=0.70$ ). The scale mean was $M=2.9$ on a 6-point Likert scale $(\mathrm{SD}=0.64)$. Endorsement was especially high with regard to those items that deal with matters of punitivity. For example, a majority of $53.2 \%$ of all respondents agreed with the item "Society should take vigorous actions against loafers and lazy people." 


\section{Political Orientation}

Participants were asked which party they would vote for if there were general elections next Sunday. The answer to this question was recoded by rank ordering the voting intentions on a left-right scale (Socialist Party $=1$; Green Party $=2$; Social Democrats $=3$; Liberals $=4$; and Christian Democrats $=5$ ).

The measurement of constructive sanctioning comprised 10 different vignettes, which described a target person acting in an antisocial way. For each vignette respondents indicated on a 7-point Likert scale whether they would ask the target-person to stop his/her antisocial behavior. The mean of this scale was $4.14(\mathrm{SD}=2.15)$, Cronbach's alpha was 0.74 .

Using the same 10 vignettes, aggressive sanctioning was measured by asking the respondents whether they would become aggressive if they (politely) asked the person to stop the antisocial behavior but he or she refused to do so. These 10 items could also be summarized into a single scale (Cronbach's $\alpha=0.84)$ the mean endorsement of aggressiveness being rather low $(M=2.3$, $\mathrm{SD}=1.69$ ).

To assess civil engagement for human rights (CEHR) a 4-item scale was developed that included the following items: (1) I am able to make an important contribution to the enforcement of human rights, (2) I take part in campaigns that are aimed at the enforcement of human rights, (3) The enforcement of human rights is not my responsibility but that of the government (to be reversed), and (4) I will join an organization like Amnesty International which aims to enforce human rights. The homogeneity of this scale was rather high (Cronbach's $\alpha=0.72$ ). The mean value of this scale (using 5-point Likert scales) was $M=3.5$ indicating quite a high level of civil engagement $(\mathrm{SD}=0.62)$.

The Attitude Toward a Military Enforcement of Human Rights (ATMEHR) was measured using the 10-item scale that was developed in Study 1. The results concerning its internal structure ant its reliability with regard to different subsamples are discussed in the Results section.

\section{Results}

\section{Internal Structure of the ATMEHR Scale}

A factor analysis of the 10 items revealed that only one factor had an eigenvalue $>1$ (eigenvalue $=5.4$ ), explaining $54 \%$ of the variance. The average interitem correlation was 0.49 (Cronbach's $\alpha=0.91$ ). This high level of homogeneity was also obtained if average interitem correlations were calculated separately for males and females ( 0.48 for males and 0.51 for females, respectively). When splitting up the sample according to the voting intentions of the respondents, the average interitem correlation was never lower than 0.37 (Cronbach's $\alpha=0.85$ ). Thus, the 
scale turned out to be homogeneous and reliable, independent from the participants' political preferences.

Respondents' average value of the scale was 3.05 ( $\mathrm{SD}=1.10)$. Thus, on average participants' attitude toward a military enforcement of human rights was slightly negative (with values theoretically ranging from 1 to 7 ). However, only a minority of all subjects unequivocally objected military engagements (for the wordings of the items, their averages, and their standard deviations see Table I, p. 82).

\section{Determinants of ATMEHR}

Table II shows the bivariate intercorrelations between the ATMEHR and the other variables. No significant relationship emerged between the two dimensions of attitudes toward the enforcement of human rights: the correlation between the ATMEHR scale and the CEHR scale was $r=0.04(p=0.32)$. Similarly, political orientations were not related to the attitude toward the military enforcement of human rights $(r=0.10 ; p=0.10)$ though participants with a left political preference showed more civil engagement for human rights than participants with a right political preference $(r=-0.22 ; p<0.01)$. The same was true for the respondents' subject of study. The values on the ATMEHR scale did not differ between law students and psychology students $(r=0.05 ; p=0.27)$, but psychology students indicated a higher civil engagement for human rights than law students ( $r=-0.19 ; p<0.01$ ). Thus, civil concern for human rights and background variables like political orientation or subject of study were rather unrelated to the ATMEHR.

Social responsibility was not significantly related to the attitude toward the military enforcement of human rights $(r=0.07 ; p=0.16)$ although those scoring high on social responsibility indicated a higher civil engagement for human rights (CEHR) $(r=0.20 ; p<0.01)$ and scored higher on constructive sanctioning $(r=$ $0.31 ; p<0.01)$.

In contrast, authoritarianism was positively related to the ATMEHR scale ( $r=0.21 ; p<0.01)$, but negatively related to civil engagement for human rights $(r=-0.19 ; p<0.01)$. Bivariate analyses further revealed that authoritarianism was highly correlated with subject of study. Law students scored higher on authoritarianism than did psychology students $(r=0.45 ; p<0.01)$. Moreover, the higher the participants' values on authoritarianism the more they indicated a preference for rather right-wing political parties $(r=0.47 ; p<0.01)$.

With regards to constructive sanctioning and aggressive sanctioning, a rather complementary picture emerged. Whereas constructive sanctioning was positively related to the CEHR scale $(r=0.24 ; p<0.05)$ and unrelated to the ATMEHR scale $(r=0.11 ; p=0.08)$, aggressive sanctioning was positively related to the ATMEHR scale $(r=0.27 ; p<0.01)$, but did not correlate with the CEHR scale $(r=0.06 ; p=0.23)$. 
Finally, although gender was not related to the CEHR scale $(r=0.07 ; p=$ 0.16 ), men indicated a significantly more positive attitude toward the military enforcement of human rights than women $(r=-0.18 ; p<0.01)$.

Next, a number of multiple regression analyses were conducted to test the simultaneous influence of personality dispositions on ATMEHR (see Table II). In the first model (Model I), all potential determinants were simultaneously analyzed. The eight independent variables were able to explain $14 \%$ of the variance of the ATMEHR scale $(F=8,2.71 ; p<0.01)$. In this analysis, aggressive sanctioning turned out to be the only significant predictor $(\beta=0.22 ; p<0.05)$.

Although problems of multicollinearity were not apparent in this analysis (the intercorrelations between the predictor variables were mostly below 0.30 , see Table I), it appeared plausible that the independent variables had "cannibalized" each other so that most of them turned out to be nonsignificant. For this reason, another regression analysis was calculated using only those predictors that had revealed a significant correlation with the ATMEHR on a bivariate level. Thus, the ATMEHR scale was regressed on authoritarianism, aggressive sanctioning, and gender of the respondents. These three predictors were able to explain $15 \%$ of the variance of the ATMEHR scale $(F=3,9.76 ; p<0.01)$. All three predictors had a significant beta weight in this analysis: authoritarianism: $\beta=0.20(p<0.01)$; aggressive sanctioning: $\beta=0.21(p<0.01)$; and gender: $\beta=-0.16(p<0.01)$.

As specified above, it appeared plausible that the degree of aggressive sanctioning might moderate the relationship between civil engagement for human rights and the attitude toward their military enforcement. To test this hypothesis an interaction term was built: first the values for aggressive sanctioning and civil engagement for human rights were centered ( $z$-standardized). Next these standardized values were multiplied with each other. Then, ATMEHR was regressed on aggressive sanctioning, civil engagement for human rights, and the interaction term of both variables, respectively (see Model III in Table III). It turned out that the interaction term indeed contributed to the prediction of ATMEHR ( $\beta=0.18$; $F$ change $=6.2 ; p<0.05)$.

Post hoc probing (following Aiken and West, 1991) revealed that the relationship between civil engagement for human rights and the attitude toward their military enforcement was nonsignificant if the level of aggressive sanctioning was low $(\beta=0.06 ; p=0.51)$. However, if the level of aggressive sanctioning was high, attitudes toward a military enforcement of human rights were the more positive, the higher the civil engagement for human rights $(\beta=0.40 ; p<0.01)$. This relationship is highlighted in Fig. 1 (showing slopes for values of aggressive sanctioning and CEHR being one standard deviation above or below the respective average values).

The beta weight of the interaction term remained significant and was virtually identical $(\beta=0.18 ; p<0.01)$, when the ATMEHR scale was simultaneously regressed on this interaction term and the CEHR, aggressive sanctioning, gender, and authoritarianism, respectively (see Model IV in Table III). 


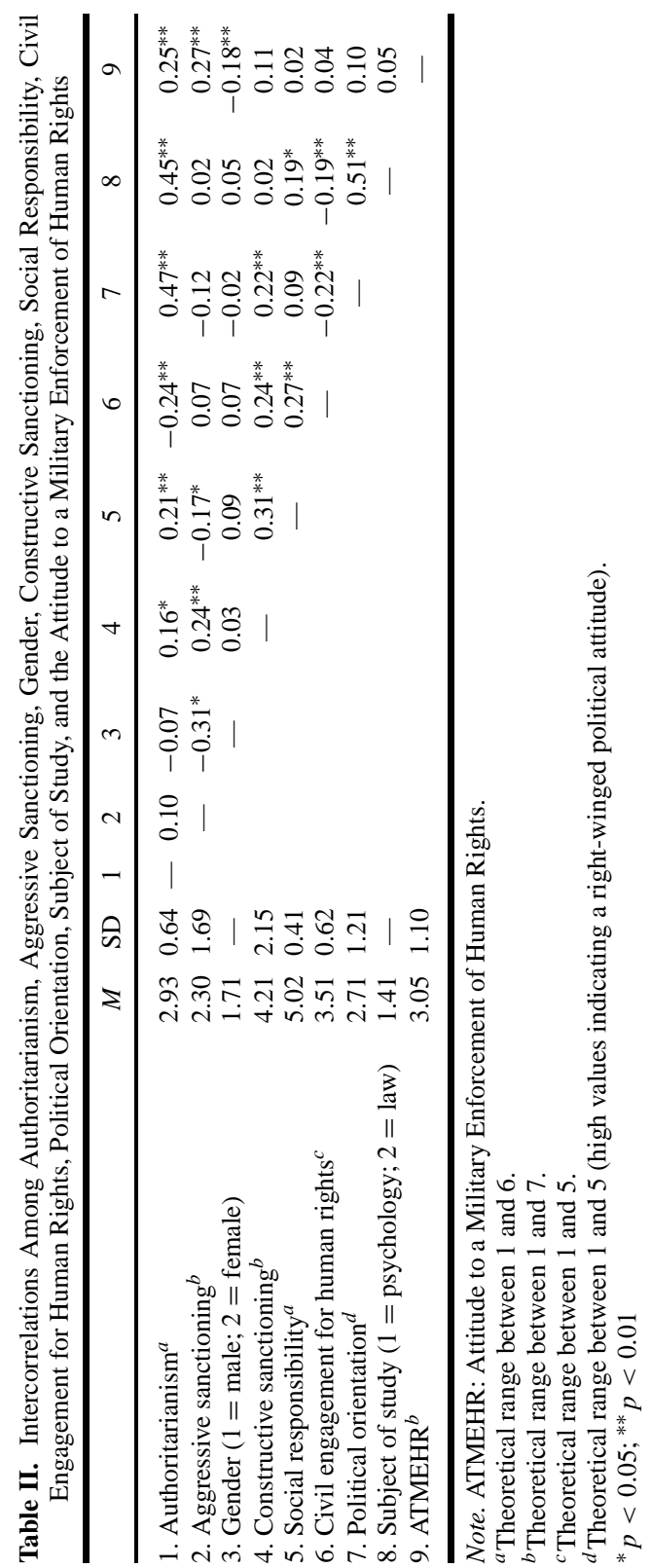




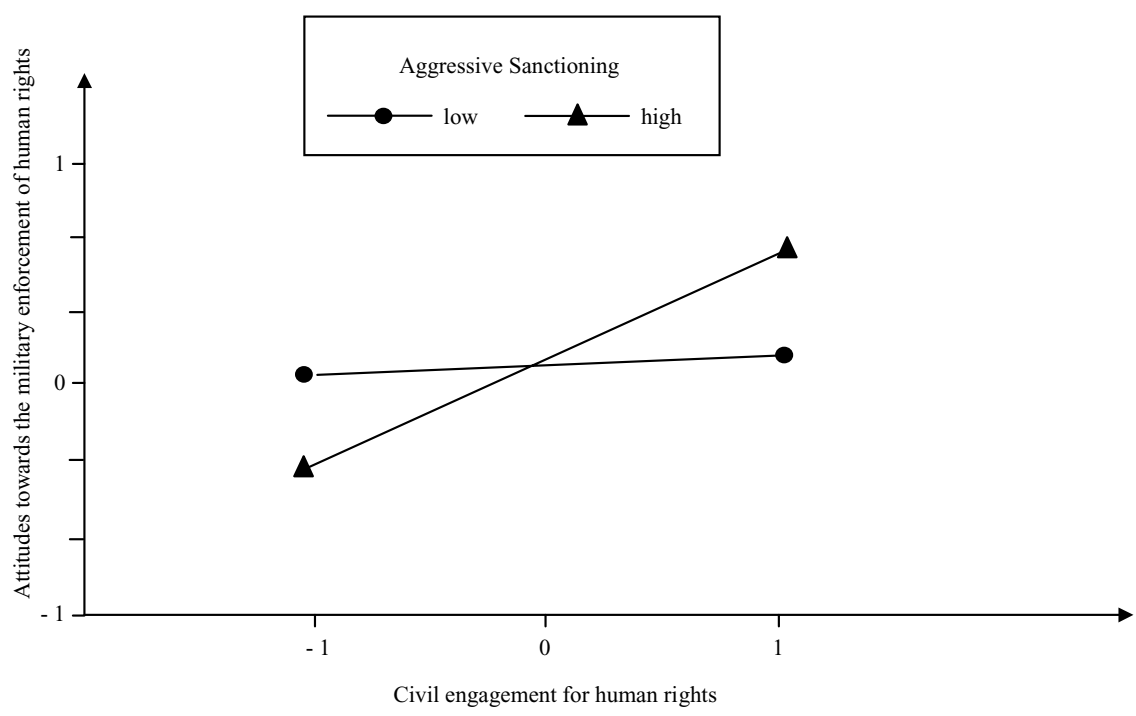

Fig. 1. The relationship between Civil Engagement for Human Rights (CEHR) and the Attitudes Toward a Military Enforcement of Human Rights (ATMEHR) dependent on different levels of aggressive sanctioning (referring to values $\pm 1 \mathrm{SD}$ ).

\section{GENERAL DISCUSSION}

The first goal of the present research was to develop and test a reliable and unidimensional scale to measure the attitude toward a military enforcement of human rights (the ATMEHR scale). Drawing on an original set of 26 items, a 10-item scale was developed that turned out to be sufficiently reliable in both

Table III. Regression Analysis to Predict Attitudes Toward a Military Enforcement of Human Rights (ATMEHR)

\begin{tabular}{|c|c|c|c|c|}
\hline \multirow[b]{2}{*}{ Independent variables } & \multicolumn{4}{|c|}{ Standardized $\beta$-coefficients } \\
\hline & Model I & Model II & Model III & Model IV \\
\hline Authoritarianism & 0.14 & $0.20^{* *}$ & & $0.22^{* *}$ \\
\hline Aggressive sanctioning & $0.22^{*}$ & $0.21^{* *}$ & $0.25^{* *}$ & $0.19^{*}$ \\
\hline Gender $(1=$ male $; 2=$ female $)$ & -0.15 & $-0.16^{*}$ & & -0.13 \\
\hline Constructive sanctioning & 0.02 & & & \\
\hline Social responsibility & -0.01 & & & \\
\hline Civil engagement for human rights & 0.07 & & 0.03 & 0.09 \\
\hline Political orientation & 0.14 & & & \\
\hline Subject of study $(1=$ psychology; $2=$ law $)$ & -0.14 & & & \\
\hline CEHR $\times$ Aggressive sanctioning & & & $0.18^{* *}$ & $0.18^{*}$ \\
\hline$F$ value & 2.717 & 9.766 & 7.662 & 7.482 \\
\hline Adjusted $R^{2}$ & 0.14 & 0.15 & 0.12 & 0.18 \\
\hline
\end{tabular}

Note. CEHR: Civil Engagement for Human Rights.

${ }^{*} p<0.05 ;{ }^{* *} p<0.01$ 
Study 1 and Study 2. Furthermore, Study 2 showed that the reliability of the scale was independent from participants' gender and their political preferences. Thus, the ATMEHR scale appears to be a robust and reliable measure of this attitude domain.

A second goal was to investigate the scale's relationship to other personality dispositions and attitudes. Quite remarkably, the ATMEHR scale turned out to be independent of whether participants cared for human rights in general (civil engagement for human rights), whether they tend to intervene in a rather friendly manner if they see others engaging in antisocial behavior (constructive sanctioning), or whether they had a high or a low level of social responsibility, respectively. Thus, the ATMEHR scale was rather unrelated to the degree of participants' concern for others. The same was true for the political orientation of the respondents indicating that the answer to the question of how to enforce human rights is rather independent of people's general political attitudes. In future studies, it would be worthwhile to investigate the relationship between the ATMEHR and general political attitudes in more detail.

As in earlier studies (Altemeyer, 1996), authoritarians revealed a rather low concern for human rights. However, a high level of authoritarianism was related to a positive attitude toward military interventions in the service of human rights. These results imply a seemingly paradoxical pattern of attitudes among high authoritarians: Although they do not care much about human rights, they are willing to go to war for their enforcement. However, the obtained results are well in line with previous research. As Altemeyer (1996) pointed out, authoritarians are willing to fight against almost every enemy as long as they assume that the government supports such aggression (cf., Rokeach, 1960). In summary, the present study indicates that people scoring high on authoritarianism are willing to go to war even if they do not really support the goal of such a war.

The more the respondents described themselves as willing to become aggressive if they witnessed antisocial behavior of others the more positive was their attitude toward military interventions. Thus, what people consider the best way to deal with international conflicts is related to the way they tend to handle everyday conflicts. On the basis of this result, it is tempting to speculate about possible relationships between a nation's willingness to go to war and its citizens' attitudes toward aggressive sanctioning (e.g., their attitude toward the death penalty).

Furthermore, aggressive sanctioning moderated the relationship of civil engagement for human rights and the ATMEHR scale. If respondents scored low on aggressive sanctioning, civil engagement for human rights was rather unrelated to the endorsement of military interventions. However, if participants scored high on aggressive sanctioning, a high level of concern for human rights was associated with a positive attitude toward military strikes. Thus, a high concern for human rights only then leads to an endorsement of their military enforcement if people tend to solve daily conflicts in an aggressive manner.

In accordance with our expectations, men indicated a more positive attitude toward military interventions than women. This relationship was still significant, 
even after controlling for other variables that were also related to gender (e.g., aggressive sanctioning) in a regression analysis. It seems that men deal with international conflicts about human rights in a somewhat different way than women. According to Gilligan (1982) and Finlay and Love (1998), women presumably tend to emphasize the suffering of innocent victims connected with military interventions, whereas men tend to emphasize more abstract principles. However, these assumed differences in moral reasoning have not been in the focus of this research and thus must be tested in future investigations. More generally, future investigations could relate the attitude toward the military enforcement of human rights to levels of moral reasoning in the tradition of Kohlberg (1984).

In future studies it would also be worthwhile to extend the number of personality dispositions that were investigated in the present research. Potential candidates would be the concept of ethnocentrism (see Moghaddam and Vuksanovic, 1990) or the dimensions of agreeableness and conscientiousness out of the Big Five personality model. Furthermore, it would be interesting to study the relationship between the ATMEHR and the attitude toward other means of enforcing human rights in nondemocratic countries (e.g., political pressure or economic sanctions).

Attitudes toward military interventions have not been investigated in past studies of attitudes toward human rights, which focused on different issues like the social representations of human rights (Doise et al., 1994). Given the fact that further military interventions by Western countries and NATO appear to be quite probable in the future, it seems worthwhile from an applied perspective to investigate what determines attitudes toward such interventions. The ATMEHR scale is a short and reliable questionnaire to measure such an attitude.

As Hänze (2001) and Fetchenhauer and Bierhoff (2001) have pointed out, the topic of military interventions for the sake of human rights implies a moral dilemma because two basic values are in contradiction with each other, namely protecting human rights vs. not using violence to solve social conflicts. Therefore, the willingness to act in a morally appropriate way (indicated by high levels of social responsibility and concern for human rights) leads neither to an unequivocally positive nor negative assessment of military interventions.

Thus, the phenomenon of military enforcement of human rights points to the fact that some new political developments in the twenty-first century are highly complex from a psychological point of view. Traditionally it was possible to contrast prosocial and antisocial behavior (Clarke, 2003). But in the case of military enforcement of human rights this distinction begins to vanish. Therefore, the question arises whether military enforcement of human rights is - from a psychological point of view-more related to prosocial or antisocial personality, respectively. Our data indicate that it is more related to antisocial personality than to prosocial personality because we found significant correlations with authoritarianism and aggressive sanctioning but not with social responsibility and constructive sanctioning. In addition, the higher endorsement of military enforcement of human 
rights by men compared with women points in the same direction. Whether or not this result is dependent on the fact that military enforcement of human rights is a new development in international politics will be seen in the future. It is possible that people will learn to relate stronger than currently prosocial motives with military interventions on behalf of human rights. This process presumably depends on situation cognition (cf., Krahé, 1992) which in turn is likely to be influenced by the way military enforcement of human rights is construed in the public discourse on justice.

\section{ACKNOWLEDGMENTS}

We thank Bram Buunk, Jan Pieter van Oudenhoven, Kenneth Dion, the research group on "prosocial dispositions and solidary behavior" at the University of Groningen, and two anonymous reviewers for their helpful comments.

\section{REFERENCES}

Aiken, L. S., and West, S. G. (1991). Multiple Regression: Testing and Interpreting Interactions, Sage, Newbury Park, CA.

Altemeyer, B. (1996). The Authoritarian Specter, Harvard University Press, Cambridge, MA.

Altemeyer, B. (1998). The other "authoritarian personality." In Zanna, M. P. (ed.), Advances in Experimental Social Psychology, Vol. 30, San Diego, CA: Academic Press, pp. 47-92.

Baxter, S., and Lansing, M. (1980). Women and Politics. The Invisible Majority, University of Michigan Press, Ann Arbor.

Berkowitz, L., and Daniels, L. R. (1964). Affecting the salience of the social responsibility norm: Effects of past help on the response to dependency relationships. J. Abnorm. Soc. Psychol. 68: 275-281.

Bierhoff, H. W. (2000). Skala der sozialen Verantwortung nach Berkowitz und Daniels: Entwicklung und Validierung [The Social Responsibility Scale of Berkowitz and Daniels: Development and validation]. Diagnostica 46: 18-28.

Bierhoff, H. W., and Rohmann, E. (in press). Altruistic personality in the context of the empathyaltruism hypothesis. European Journal of Personality.

Braithwate, V. (1998). The value orientations underlying liberalism-conservatism. Pers. Individ. Differ. 25: 575-589.

Clarke, D. (2003). Pro-Social and Anti-Social Behaviour, Routledge, London.

Doise, W., Spini, D., Jesuino, J. C., Ng, S. H., and Emler, N. (1994). Values and perceived conflicts in the social representations of human rights: Feasibility of a cross-national study. Swiss J. Psychol. 53: $240-251$.

Feather, N. T. (1996). Reactions to penalties for an offence in relation to authoritarianism, values, perceived responsibility, perceived seriousness, and deservingness. J. Pers. Soc. Psychol. 71: $571-587$.

Fetchenhauer, D., and Bierhoff, H. W. (2001). Zivile und militärische Durchsetzung der Menschenrechte [Civil and military enforcement of human rights]. In Bierhoff, H. W., and Fetchenhauer, D. (eds.), Solidarität [Solidarity], Leske \& Budrich, Opladen, Germany, pp. 123-147.

Fetchenhauer, D., and Huang, X. (in press). Justice sensitivity and behavior in experimental games. Pers. Individ. Differ.

Finley, B., and Love, G. D. (1998). Gender differences in reasoning about military intervention. Psychol. Women Q. 22: 481-485. 
Gilligan, C. (1982). In a Different Voice, Harvard University Press, Cambridge, MA.

Hänze, M. (2001). Ambivalence, conflict, and decision making: Attitudes and feelings in Germany toward NATO's military intervention in the Kosovo war. Eur. J. Soc. Psychol. 31: 693-706.

Kerlinger, F. N. (1984). Liberalism and Conservatism: The Nature and Structure of Social Attitudes, Erlbaum, Hillsdale, NJ.

Kohlberg, L. (1984). The Psychology of Moral Development, Harper, San Francisco.

Krahé, B. (1992). Personality and Social Psychology. Toward a Synthesis, Sage, London.

Moghaddam, F. M., Slocum, N. R., Finkel, T. M., and Harré, R. (2000). Toward a cultural theory of duties. Cult. Psychol. 6: 275-302.

Moghaddam, F. M., and Vuksanovic, V. (1990). Attitudes and behavior toward human rights across different contexts: The role of right-wing authoritarianism, political ideology, and religiosity. Int. J. Psychol. 25: 455-474.

Schmitt, M., Neumann, R., and Montada, L. (1995). Justice sensitivity. Soc. Justice Res. 8: 385-407.

Spini, D., and Doise, W. (1998). Organizing principles of involvement in human rights and their social anchoring in value priorities. Eur. J. Soc. Psychol. 28: 603-622.

Staerklé, C., Clémence, A., and Doise, W. (1998). Representation of human rights across different national contexts: The role of democratic and nondemocratic populations and governments. Eur. J. Soc. Psychol. 28: 207-226. 
Copyright of Social Justice Research is the property of Kluwer Academic Publishing and its content may not be copied or emailed to multiple sites or posted to a listserv without the copyright holder's express written permission. However, users may print, download, or email articles for individual use. 
Copyright of Social Justice Research is the property of Springer Science \& Business Media B.V. and its content may not be copied or emailed to multiple sites or posted to a listserv without the copyright holder's express written permission. However, users may print, download, or email articles for individual use. 